Faculty of Business

Faculty Publications

This is a post-print version of the following article:

Does Resource Diversity Confer Organizational Autonomy In Arts Organizations? Extending Resource Dependence Theory, The Journal of Arts Management, Law, and Society

Peter D. Sherer, Roy Suddaby, and Mary Rozsa de Coquet

2019

The final publication is available at:

https://doi.org/10.1080/10632921.2018.1559265

Citation for this paper:

Sherer, P. D., Suddaby, R., \& Coquet M. R. (2019). Does resource diversity confer organizational autonomy in arts organizations? Extending resource dependence theory. The Journal of Arts Management, Law, and Society, 49(4), 224-241. https://doi.org/10.1080/10632921.2018.1559265 


\title{
Does Resource Diversity Confer Organizational Autonomy in Arts Organizations? Extending Resource Dependence Theory
}

\author{
Peter D. Sherer* \\ Haskayne School of Business \\ University of Calgary \\ Roy Suddaby \\ Peter B. Gustavson School of Business \\ University of Victoria \\ $\&$ \\ Liverpool University Management School \\ Liverpool University \\ Mary Rozsa de Coquet \\ Rozsa Foundation \\ Calgary, Canada
}

* The order of the authors is alphabetical; they share equally in the work.

We acknowledge the generous financial support of the Rozsa Foundation and the Alberta Foundation for the Arts, the Edmonton Arts Council and the Canada Council for the Arts. We also highly appreciate Scott Rankin's efforts in assembling and analyzing the data. 


\section{Introduction}

Resource dependence theory (RDT) has proven to be a powerful lens for understanding how organizations manage their external relationships. A critical element of the theory is the role of power and the understanding that organizations actively manage the degree to which they depend upon other powerful organizations (Pfeffer \& Salancik, 1978). Typically, the organizations most likely to exert power over a firm are those that provide the firm with critical resources (Ulrich \& Barney, 1984). As a result, RDT argues that firms adopt strategies designed to manage their external dependencies.

Since its original articulation, RDT has become a dominant rationale for explaining a range of organizational behaviours, including mergers, joint ventures, the constitution of boards of directors, executive succession and firm political activity (Hillman, Withers \& Collins, 2009). Despite its success, the theory has been criticized for weak construct clarity (Casciaro \& Piskorski, 2005) and the lack of specificity in determining which types of strategies actually confer autonomy (Drees \& Heugens, 2013). While these studies begin with a critique of RDT, ultimately, they offer valuable refinements of the theory.

Most prior studies have assumed a high degree of power imbalance between the focal organization and those organizations in the external environment that provide critical resources (Casciaro \& Piskorski, 2005). They do so because most empirical studies of RDT are dyadic - i.e. they examine a power differential that exists between the focal organization and a single external resource provider. Few studies, if any, have examined how organizations manage their external dependencies when they have access to multiple resource providers. As a result, we know little about how organizations manage their resources in order to reduce dependency. 
Does an organization achieve greater autonomy when they have a portfolio of alternative resources to draw from? We answer this question through an analysis of nonprofit performing arts organizations. Like for-profit organizations, non-profit arts organizations must ensure sustainable financial performance. However, unlike for-profit organizations, arts organizations pursue non-financial strategic objectives as ends in themselves. That is, in addition to earning revenue, arts organizations also pursue educational, community engagement and aesthetic goals. While these objectives do not directly generate revenue, they do generate different forms of legitimacy, each of which can be causally related to different sources of funding. Moreover, arts organizations are largely dependent on a range of different types of patrons, each of which stands in a dyadic relation of power over the arts organization. Indeed, one can see the power dependence relationship between donors and arts organizations as more acute than might be observed in for-profit firms. As such, performing arts organizations offer an ideal context in which to conduct a more nuanced analysis of the core tenets of RDT.

Our overarching research question, thus, is does access to a broader portfolio of resources confer greater autonomy on an organization? Alternatively, can organizations reduce their dependence by diversifying their resources? We address this question by pursuing two subsidiary questions. First, we ask whether specific types of revenue differentially contribute to organizational autonomy. Second, we ask whether more diversified resources - access to a portfolio of resources - grants organizations the autonomy to engage in a broader set of activities.

To foreshadow our results, we find that different sources of funding - earned revenue, private philanthropy, corporate philanthropy and government -generate different 
types of organizational activity, not all of which indicate greater organizational autonomy. We propose a configurational model of RDT in which different constellations of resources generate different degrees of independence. We find strong support for the notion that access to a portfolio of resources rather than a single source helps an organization to achieve independence from its environment and pursue self-interested goals.

\section{The Empirical Context: Arts Organizations}

The non-profit performing arts sector offer an ideal context to study RDT because arts organizations are highly dependent upon their external environment. As such, arts organizations exemplify the main tenets of RDT, which argues that internal demands for organizational efficiency are often less important to organizational survival than effectiveness in building relationships with external partners that provide critical social, political and economic resources.

Early studies of organizations assumed that organizational success and survival was determined, largely, by an organization's internal characteristics - i.e. the efficiency of how the organization structured the productive relationships between employees (Katz \& Kahn, 1978). In the latter 1970's, however, researchers introduced the term "open-systems theory" to describe how many organizations succeed, not because of internal efficiencies, but because of their ability to manage relationships with their external environment - i.e. with regulators, suppliers, customers and with other competitors. According to open systems theory, getting preferential access to resources, both material and symbolic, was the primary determinant of organizational success. RDT, which pointed to the success of large military suppliers which succeeded not by efficiency but by their ability to manage external dependencies, exemplified the core logic of open systems theory. 
Just as RDT exemplifies open systems theory, so too do performing arts organizations exemplify the core elements of RDT. Arts organizations succeed less by their ability to organize efficiently and more by their ability to manage their relationships with external partners. Perhaps the best articulation of the external dependency of arts organizations in the sociological literature is captured in Becker's (1982: x) term "art worlds" which he defined as a "...network of people whose cooperative activity, organized via their joint knowledge of conventional means of doing things, produce(s) the kind of art works that art world is noted for". Empirical analyses of art worlds reinforce the notion that arts organizations exist in a social field of different types of firms and actors consumer, suppliers, producers and critics - who interact frequently and deterministically with each other (Thornton, 2008). Notably, Becker shares with RDT a focus on the critical importance of external resources in defining the parameters of art worlds and in determining the success and survivability of individual artists and arts organizations. Mobilization of resources, Becker observes, is the foundational characteristic of art worlds because art is fundamentally a collective not an individual act. Successful artists and art organizations, therefore, succeed largely on their ability to collectively mobilize both material (i.e. economic or physical resources) and social (legitimacy, power, status and reputation) resources (Baumann, 2006).

Both the sociology of art and resource dependence theory, thus, share an interest in understanding how the absence or presence of internal resources affects the autonomy of an organization. The objective of any organization or artist is to strategically manage external dependencies in order to maintain internal autonomy. Autonomy is defined in organization theory as an organization's “...freedom to make its own decisions about the 
use and allocation of its internal resources without reference or regard to the demands or expectations of potential linkage partners" (Oliver, 1991: 944-5). Both arts organizations and organizational theorists understand and struggle with an implicit trade-off between legitimacy (maintaining relationships with external providers of material and symbolic resources) and autonomy (maintaining the freedom to use those resources internally in an independent way).

Perhaps the strongest theoretical contribution that RDT can offer researchers interested in arts organizations is in offering a rigorous conceptual lens through which aesthetic and organizational autonomy can be understood. We see three possible contributions. First, while the concept of power is central to RDT, critics note that it is particularly difficult to operationalize in the context of inter-corporate relationships. As we demonstrate, power relationships are both more pronounced when we analyze the relationship between arts organizations and their various philanthropic patrons. Second, as noted above, most empirical studies of RDT in the for-profit sector study dyadic relationships between a single resource provider and a focal organization. Non-profit arts organizations, however, have had to cultivate multiple sources of revenue, each of which reflect different interests and demands on the focal organization. Arts organizations, thus, afford the opportunity to study the varied effects of different power interests on the autonomy of a single firm. Finally, in contrast to most for-profit organizations, non-profit arts organizations engage in a broad range of activities by which their overall performance is measured. For-profit firms, by contrast, are measured largely by their ability to earn revenues and generate profits. As such, these arts organizations provide a greater repertoire of behaviours through which we can assess the degree of autonomy a focal firm has 
achieved over its resource provider. We elaborate each of these observations in the balance of this section.

Power Differences: Performing arts organizations have always been highly dependent on powerful patrons for their existence (DiMaggio, 1991; Dewey, 2003). Historically, wealthy private philanthropists were the most prominent sources of revenue for artists and patrons such as the Medici family could determine their fame or demise (Chambers, 1970). In the modern era, governments have largely usurped the role of private patronage in the arts (Froelich, 1999) and most performing arts organizations in both Canada and the US are highly dependent upon funding from a range of public agencies such as the National Endowment for the Arts (NEA) in the US or the Canada Council for the Arts in Canada (Schatteman \& Bingle, 2017). In an extensive study of the relationship between a range of different types of non-profits and public agencies in New York State, using a resource dependence framework, Saidel (1991) concluded that arts organizations reported much higher levels of dependence on public agencies than any other category of non-profit.

Resource Diversification: Since the 1990s, governments have gradually but consistently withdrawn funding for the arts. Faced with increased deficits, government funding for the arts decreased significantly in Europe (Mulcahey, 2000) and North America (Wyxzomirski, 2002) beginning in the 1990s and at an accelerated pace in the early 2000s (Schatteman \& Bingle, 2017). As a result, arts organizations have had to diversify their sources of revenue, looking increasingly to corporate and private philanthropy as a source of revenue (Froelich, 1999). 
Beginning in the 1960's, corporations emerged as another powerful source of financial support for arts organizations, fueled by increasing profits and supportive taxation policies (Kirchberg, 2003; Alexander, 1996). As a result, performing arts organizations now look to four basic categories of funding; government funding, private philanthropy, corporate philanthropy and earned revenue. As we elaborate below, each of these sources of funds comes with different expectations of the degree of autonomy arts organizations may enjoy in their performative behavior.

Firm Performance/Behavior: Performing arts organizations engage in three basic types of performances. First, a considerable proportion of time is typically devoted to community outreach and educational activities. These activities serve several roles for the arts organization. They provide legitimacy for the organization in the community at large. More instrumentally, they enhance the public profile of the arts organization and, not inconsequentially, the reputation of the organization's patron or donor. Because this category of activity provides publicity, legitimacy and builds reputation, one might logically conclude that this type of organizational action is a preferred outcome of all of the financial patrons of arts organizations - private philanthropists, corporate donors and public agencies. Because this type of activity does little to lessen the degree of dependence of the performing arts organization on the patron, we can logically conclude that this activity is not a preferred outcome of the focal organization.

Second, arts organizations devote considerable time to staging performances that generate paying audiences and result in earned revenue. Empirical research has shown that not for profits in North America typically receive less than half of their overall income from earned revenue (Foster \& Loch, 2005). Significantly, despite the pressure to diversify 
income sources, the proportion of total income derived from earned revenue has not changed over the past several decades (Foster \& Loch, 2005). Foster \& Loch (2005) suggest that while higher earned revenue is often a preferred outcome of donors, both private and public, most artistic driven organizations find the singular pursuit of profits detracts from their core mission of generating creative or more innovative productions. This is consistent with prior research on creativity (Amibile, 1985) which suggests that creative professionals are much more motivated by aesthetic novelty and innovation than by extrinsic monetary reward.

We can, therefore, view the behavioural outcomes of performing arts organizations as a simple hierarchy, with innovation being the ultimate goal of the performing arts organization and the other two categories of activities (community outreach/education and earned revenue performances) as activities that satisfy the ambitions of their patrons. These latter activities, thus, increase their dependency on patrons and distract them from their preferred autonomous activity of creative innovation.

\section{Resource Heterogeneity and Strategic Choice}

Based on the above we can generate a series of predictions about how performing arts firms manage their sources of revenue in order to reduce their dependence and aquire the ability to pursue preferred activities of aesthetic innovation and creativity. Similarly, we can also generate some predictions about how different types of dependency, as reflected in different types of patrons, can encourage arts organizations to engage in distinct types of activity. We begin with the latter question and sequentially offer predictions of how each of the different sources of funding - corporate philanthropy, private donors and 
government support - create different dependencies that generate distinct behavioural outcomes in performing arts organizations.

Corporate Funding: Corporate motives for public philanthropy have changed over time. Several decades ago, much corporate giving was largely altruistic and often based on a diffuse and unfocused commitment to "giving back to the community" (Varadarajan \& Menon, 1988). Increasingly, however, corporate giving is strategic designed to align the interests of the community with the corporate donor. Porter and Kramer (2001) distinguish between "cause-related marketing" in which the corporate donor simply tries to achieve positive public relations and enhance their reputation in the community by giving to select high-profile causes, and "true strategic philanthropy" in which corporations target donations to "areas of competitive context where the company and society both benefit" (Porter \& Kramer, 2001: 6).

Despite the interest in promoting strategic philanthropy, empirical studies indicate that most corporations are still focused on cause-related marketing. A review of corporate cause-related philanthropy reports that cause-related marketing in the USA is worth 9 per cent (\$828 million) of the America sponsorship market and has been one of the areas of growth over the last few years (IEG, 2001). Cause-related philanthropy, at its core, is a marketing activity designed to enhance the image and reputation of a corporation by broadening its exposure to large audiences within a given community (Adkins, 2007). Long standing empirical research demonstrates that corporate donations to performing arts organizations tend to favour activities that raise the public profile of the corporation while avoiding controversial issues that may generate negative publicity or adversely affect the donor's reputation (Useem, 1987). 
Saloman (1987), in a study of over three thousand not-for-profits, found that corporate donations for the arts generally focus on high visibility outcomes. Kelly (1998) similarly observed that corporate donations are often directed by the donor's public relations team and as a result adopt their publicity objectives. For this reason, a common metric used by many corporations in evaluating their funding is how many people are impacted (Castenar \& Campos, 1998). As such, we believe that there is a relationship between corporate donations to performing arts organizations and expectations that the recipient organization will engage in activities that maximize audiences - either in community outreach and/or attendance at live performances. Accordingly, performing arts organizations that are dependent upon the resources of corporate donors will emphasize those behavioural activities:

Hypothesis 1A: Corporate funding will be positive related to attendance at live performances and to cultural/educational outreach.

Moreover, we further predict that these behavioural outcomes will occur at the expense of the autonomy of the performing arts organization. That is, they will have less time and resources available to pursue their aesthetic mission by generating innovative new art:

Hypothesis 1B: Corporate funding will be negatively related to aesthetic/artistic innovation.

Private Philanthropy: While there has been considerable philosophical debate about the varied motives for private philanthropy (DiMaggio, 1986a), most empirical studies of private subsidy of the arts suggests that individual, family and closely-held foundations tend to pursue the same types of cause-related marketing as do corporations. So, for example, in a study of 478 US businesses support of arts organizations, privately- 
held businesses of medium size (300 to 500 employees) funded arts organizations with a view to enhancing their profile and reputation in the community (File \& Prince, 1988). In a study of US based performing arts organizations, DiMaggio (1986b) reports that private philanthropy, particularly from large foundations, tends to support traditional and established artistic programs and offers little financial support for artistic innovation. Kramer (2009) extends this observation to small private philanthropic foundations, which he concludes, confine their donation decisions to relatively conservative ends.

Private philanthropy tends to be focused on high visibility performances and the creation of professional or bureaucratic structures inside arts organizations. As a result, mission drift and artistic goal displacement in firms that receive private philanthropic support is "likely greater than that of corporate philanthropy" (Froelich, 1999: 253). Instead of embracing innovation or "catalytic philanthropy", for most private donors "philanthropy is about deciding which nonprofits to support and how much money to give them" (Kramer, 2009: 32).

Based on these observations we believe that, while it is possible individual patrons or private foundations may have special missions, they most likely favour the status quo and rather than promote artistic innovation in a recipient organizations, give money in order to reinforce what the organization already does. While we would expect that individual philanthropy might be less motivated by marketing aims than corporate donors are, they will be more positively motivated to promote educational/cultural behaviours and not motivated to promote aesthetic autonomy or artistic innovation in performing arts organizations. Therefore we predict the following hypotheses:

Hypothesis 2A: Individual philanthropy will be positively related to attendance at live performances and cultural/educational outreach. 
Hypothesis 2B: Individual philanthropy will be negatively related to aesthetic/artistic innovation.

Government Funding: Of the four different sources of revenue for performing arts organizations, the motives for government support have received the most empirical attention. Like corporate giving, government support for the arts has evolved over time. As noted above, since the latter part of the last century, government support for the arts has been decreasing relative to the other three categories of revenue (Schatteman \& Bingle, 2017). Moreover, government accountability for arts support over the same time period has been increasing (Froelich, 1999).

Fundamentally, government support for the arts is premised on serving the broadest interests of the constituent community or public. As such, we would expect that government support for the arts will be dependent upon the recipient organizations demonstrating positive support to cultural and educational outreach in the community. However, governments are increasingly subject to reduced government budgets and intensified scrutiny regarding public accountability. As such, we would also expect to see government funding linked to expectations that the recipient arts organization will try to enhance their efforts to earn revenue and attendance at live performances while adopting conservative or risk-averse attitudes to supporting artistic innovation.

As such, we predict the behaviour expectations from a dependency on government resources by performing arts organizations to be quite similar to those associated with corporate sponsorship:

Hypothesis 3A: Government support will be positively related to cultural/educational outreach, and attendance at live performances. 
Hypothesis 3B: Government support will be negatively related to aesthetic/artistic innovation.

Earned Revenue: Of the four sources of resources, the ability to self-generate revenue logically grants an artistic organization the highest degree of autonomy from other organizations. In this regard, we expect that performing arts organizations that derive more of their revenue from earned revenue will have greater autonomy to pursue their core artistic mission. That is, earned revenue should promote innovation.

That said, prior research suggests that commercial success can actually suppress artistic innovation (Castenar \& Campos, 2002) just as commercial success often gets in the way of not-for-profits' capacity to pursue their social mission (Foster \& Bradach, 2005). So, for example, Glynn's (2000) study of the Atlanta Symphony Orchestra demonstrated the tension that occurs when the board of the performing arts organizations wants to pursue an agenda of maximizing the audience (and revenue) by making classical music more popular and the performing artists who seek to improve their professional skill and demonstrate a commitment to the aesthetic ideals of the traditional canon of classical music. The organizational structure of arts organizations encourages them to simultaneously pursue both commercial and artistic interests, sometimes at the expense of both (Lampel, Lant \& Shamsie, 2002).

Based on this nuanced insight we predict that performing arts organizations that depend largely on earned revenue will seek to pursue all available behavioural outcomes. Accordingly, we hypothesize as follows:

Hypothesis 4: Funding from earned revenues will be positively related to attendance, cultural/educational outreach and innovation. 
Resource Heterogeneity and Autonomy: What remains unaddressed in the foregoing discussion is our primary interest in understanding how organizations can reduce their dependency on a single dyadic relationship when they have multiple sources of revenue. That is, can organizations manage their dependency by managing the portfolio of resources available to them? Castenar and Campos (2002: 40) observe that: “...one could argue that arts organizations are more likely to engage in artistic innovation if they are not dependent on any single patron, whether public or private" [emphasis added]. Their argument can be broadened to suggest that as arts organizations broaden their portfolio of resources, they become less dependent upon a single patron and therefore are more likely to pursue their core mission of artistic and aesthetic innovation.

The above argument suggest a configurational view of funding diversity which looks to the specific forms of funding and posits differential effects and a hierarchy in their relationships with the behavioural outcomes. The specifics of this argument are shown in Table 1. Corporate funding, individual philanthropy, and government funding are used principally to meet the demands of resource providers. Only earned revenues allows for organizations to engage in more autonomous behaviour, namely, artistic innovation. Hence we hypothesize the following:

Hypothesis 5: There is a configuration of funding diversity by which corporate funding, individual philanthropy and government funding service key external resource providers through attendance and outreach; earned revenues provides organizations with the autonomy to pursue innovative activities.

\section{Methods}

To address our hypotheses, we drew from the CADAC (Canadian Arts Data/Donees sur les arts au Canada) database. CADAC is a web-based application 
dedicated to the collection, dissemination and analysis of financial and statistical information about Canadian arts organizations. CADAC has two parts: a financial form survey (which asks respondents to provide information on their organization's financials) and a statistical form survey (which asks respondents to provide information about the activities that their organization takes part in, their size in number of employees, and other aspects of these organizations, such as the size of their board).

A joint effort of arts funders across the country, CADAC provides a simplified process for arts organizations applying for operating grants. Arts organizations making application to multiple funding agencies submit their financial and statistical information in a single format, to a single source. They have access to their own historical data and to reports both on their own organizations and comparisons to all similar organizations in the database. We note that the database consists of a broad range of different types of arts organizations including those engaged in visual arts, new media, literary arts, arts education, arts service, community arts, multidisciplinary arts, and traditional or classical performing arts (i.e. symphony, ballet etc.). Our use of the term "performing arts organizations" is inclusive of all of these types of organizations.

Public sector funding agencies have immediate access to current and consistent data for all the arts organizations they fund. Aggregate data across CADAC are also accessible, allowing for reliable and consistent analysis of the Canadian arts sector. Individually and collectively, funding agencies are able to report on the health of the field and the impact of the arts in their communities.

Our sample consisted of arts organizations distributed among different disciplines as specified in Table 2. The lowest number of organizations was 537 in 2009; the highest 
number of organizations was 602 in 2011. Theatre organizations were the largest number of arts organizations, followed by visual arts, music, media and dance, and literary arts (with 6 for most years). The sample ranged from just over 25 performing arts organizations that had less than 50,000 in total funding to seven organizations with over 50 million in funding. The distribution of the sample organizations among different categories of performing arts is outlined in Table 2.

\section{INSERT TABLE 2 ABOUT HERE}

Dependent Variables: We assessed arts' organizations on three key organizational activities making use of the CADAC statistical form survey. For educational and cultural outreach (Outreach), we made use of several questions that asked respondents to assess the number of activities their organization had that involved arts education and arts learning activities/programs to the outside community. To assess audience impact (Attend), we examined the total attendance that an organization had in a given year. We examined innovativeness (Innov) through the number of new works that an organization had for a given year. The measure makes use of a self-referent conceptualization of innovativeness (Castenar \& Campos, 2002). All of our dependent variables were measured in $\mathrm{t}^{+1}$.

We transformed both attendance (lnAttend) and educational and cultural outreach (lnOutreach) using the natural logarithm given concern that outliers would have undue influence on the estimates. Since there is no logarithmic value for values of 0 , rather than omit them, we added 1 and took the natural $\log$, which resulted in those values again equalling 0 . Innovativeness as comprised of the number of new works did not have the 
same degree of outliers as the other two dependent variables. We, therefore, left it as the number of new works.

Independent Variables: The key independent variables had to do with funding sources and came from the CADAC financial form survey. The independent variables were the dollar amounts of earned revenues (Earned), corporate funding (Corp), individual philanthropic donations (Indiv), and government funding (Govt). Smaller categories of funding (e.g., investment returns) were omitted because the regression analyses cannot be run with $100 \%$ of the funding sources in the equations. All of these variables were measured at $\mathrm{t}$ (relative to the dependent variables at $\mathrm{t}^{+1}$ ).

We transformed these measures using the natural logarithm given our concern that some outliers would have undue influence on the estimates. Since there is no logarithmic value for values of 0 , rather than omit them, we added 1 and took the natural log, which resulted in those values again equalling 0 .

We assessed funding diversity by looking at the pattern of the coefficients for these variables in relation to the dependent variables. Our approach here is to look at the configuration of effects. Also, as specified below, we controlled for the overall or general diversity in funding that was not specific to the funding sources.

Control Variables: We controlled for several key variables. Critically, we controlled for the overall or general diversity in funding using the commonly used Herfindahl index (Herf). This variable allows us to control for overall diversity in funding that is non-specific in nature. In this regard, two organizations might have the same overall diversity score but actually have differences in their specific funding sources. 
Herf was calculated as the summation of the squared decimals of the four funding sources $(\mathrm{fs}): \sum(\mathrm{fs})^{2}$. The Herfindhal index takes on a value of 1 when there is total concentration of funding and approaches 0 when there is no concentration of funding. For example, an organization that received $50 \%$ of its funding from two sources would have a Herfindahl index of $.50\left(=.50^{2}+.50^{2}+0^{2}+0^{2}\right)$ whereas an organization that received all of its funding from one source would have a Herfindahl index of $1.00\left(1.0^{2}+0^{2}+0^{2}+0^{2}\right)$. As such, a lower score indicates a more diversified funding mix. Herf was measured at $t$ relative to the dependent variables at $\mathrm{t}^{+1}$.

We created a series of dummy variables to control for discipline differences across arts organizations. Since there were 6 different disciplines, we coded for 5 dummy variables. We treated dance companies as the referent discipline. Thus, our results for the 5 discipline dummy variables tell us the difference between that discipline and dance companies. We also controlled for year given the variation that has been observed in nonprofit funding and activities (Castenar \& Campos, 2002).

We additionally controlled for size in employment, although as mentioned it is highly correlated with our funding measures. We transformed size using the natural logarithm given several outliers. We show the results with and without size in the equation, although the results do not vary much.

Analysis of Data: To test the hypotheses, we created a panel data set of from 20092013 for organizations in the CADAC data set, which amounted to 2893 organizationyears. We used data on the independent variables from year $t$ (e.g., 2009) to predict the dependent variables in $\mathrm{t}^{+1}$ (e.g., 2010), which reduced our data set to an $\mathrm{N}$ of 2286 organization-years after accounting for missing data. Our panel is largely balanced but 
there are organizations for which there are not data for a given year, particularly 2009 and 2013. For a given year, an organization may have dropped out or appear for the first time. We employed random effects models with the four dependent variables since the key independent variables for organizations did not vary significantly from year to year.

Descriptive Statistics: Table 3 provides means and standard deviations for the dependent variables in the regression equations. Total attendance per year averaged almost 34,000, the number of new educational/cultural outreach activities was just over 100 , and the number of new works was just over 22 .

INSERT TABLE 3 ABOUT HERE

Table 3 also provides means and standard deviations for the key independent variables in the regression equations. Earned revenues averages almost 640,000 , followed by government funding at almost 560,000. Individual philanthropic funding averages just over 130,000, while corporate funding is less than 100,000. These variables without their logarithmic transformations have considerable variation, as reflected in their large standard deviations. In part, this variation reflects the very substantial size and discipline differences in these organizations, which we control for in the regression models.

Table 4 provides the correlations among the independent and dependent variables. It is clear $\ln$ Size has a strong correlation with lnGovt and also with $\operatorname{lnEarned}$. We, therefore, included lnSize in the models as well as omitted it to see if it resulted in major differences in the results. Several of the other higher correlations, such as the relationship between lnEarned and lnGovt might also be due to size. Therefore, controlling for size is 
important to ruling out a spurious relationship between these funding sources and our dependent variables.

\section{INSERT TABLE 4 ABOUT HERE}

\section{Results}

Our regression results are shown in Table 5. Note that we present the regression results with and without size in the equation because of the strong correlation of size to $t$. However, the results with and without $\ln$ Size are quite similar. We are mindful that the independent variables - the sources of funding - are not necessarily substitutes for each other but might as easily be complementary to each other.

\section{INSERT TABLE 5 ABOUT HERE}

Our first three hypotheses predicted that arts organizations that are funded by external donors - corporate, private or government - would be more likely to engage in behaviours that maximized their (and their donors) exposure to the external community. We thought this would occur because each of these activities serve the primary objective of generating publicity for the donor and the secondary objective of encouraging overtly philanthropic behaviours that directly engage the organization and, by association, the donor, with different elements of the external community.

Stated in theoretical terms, we assumed that the organizations' external dependence would encourage them to engage in externally oriented activities that serve the external interests of the donor rather than the internal ambitions of the organization. Conversely, we predicted that arts organization that are funded by external donors would be less likely 
to engage in self-interested aesthetic objectives such as devoting time and energy to creating innovative new artistic productions.

Our results, largely, support this argument. Hypothesis 1A, which predicted that corporate funding would be positively related to high attendance at live performances and high engagement in cultural and educational outreach programs, is supported. Hypothesis $1 \mathrm{~B}$, which predicted that corporate funding will be negatively related to aesthetic/artistic innovation was not supported. The results do not show a significant relationship between corporate funding and aesthetic/artistic innovation.

We observe similar results for Hypothesis 2A and B, which demonstrate a positive relationship between individual or private philanthropy and high engagement in cultural and educational outreach. However, individual or private philanthropy was not related to attendance at live performances. Private philanthropy was negatively but not significantly related to artistic innovation.

We see similar results for government funding, Hypotheses 3A and 3B, as with corporate funding. Government funding is significantly and positively related to both high attendance at live performances and cultural and educational outreach activities, but does not relate to innovation.

Hypothesis 4 predicts earned revenues will be related positively to all three behavioural outcomes. That is, earned revenues leads to higher attendance at live performance, higher engagement in educational and cultural outreach and higher degrees of artistic innovation. A key difference with this hypothesis is our argument that arts organizations that relied heavily on earned revenues were more likely to gain the autonomy 
to engage in self-interested activities that would promote their core mission of pursuing artistic novelty and innovation. Our results support this prediction.

Our final hypothesis, 5, the culmination of the prior hypotheses, predicted that the pattern of funding sources in the resource portfolio of the arts organization would be reflected in the pattern of the outcome activities of the organization. We found positive support for this argument. We can see an emerging configuration between sources of revenue and performance outcomes in which certain sources of revenue are clearly associated with behaviours. Only earned revenue, as noted above, relates positively to artistic innovation.

We note also the overall diversity measure, as captured in the Herfindahl index, showed limited support. It consistently related only to attendance at conventional levels of significance. Finally, we find size significantly relates positively to both educational and cultural outreach and attendance, but not to innovation.

Viewed collectively, we see that in order to achieve all of the expected behavioural outcomes, a performing arts organization would have to gather the full portfolio of available resources. We discern a hierarchical configuration between resources and outcomes where, at the base, private philanthropy will move arts organizations to engage in educational and cultural outreach, corporate and government funding will support those outcomes and also add to attendance at live performances. However, if a performing arts organization wants the freedom to engage in artistic innovation, they will have to add earned revenue to their portfolio of resources. Our configurational model of resource acquisition, therefore, begins to resemble a hierarchy of resources.

\section{Discussion and Conclusion}


Our research offers two distinct contributions to, and extensions of, RDT. First, we move beyond traditional views of dyadic relationships between a focal organization and a single resource provider to adopt a more realistic approach of multiple resources that can be devoted to multiple behavioural outcomes. We propose revising our understanding of RDT by viewing it through a configurational lens. Second, and arguably more provocative, we identify an emerging model of resource hierarchy. We elaborate both of these contributions below.

A Configurational View: Most applications of RDT have been dyadic. That is, they examine how focal organizations respond to pressures imposed on them by a single organization. Researchers are beginning to more accurately theorize how power differences between a focal organization and a resource provider induce different types of behaviours as the focal organization tries to manage its dependency (Casciario \& Piskorski, 2005). Our study extends this approach by analyzing the more realistic and complex scenario in which a focal organization has access to multiple resource providers and engages in multiple outcome behaviours. This analytic approach, we believe, is more consistent with the opensystems understanding of organizations within which RDT was originally conceived.

Our results support a configurational view of resource dependencies. Different sources of funding come with different expectations, constraints and result in different types of organizational behaviour. Our results demonstrate that organizations seeking the greatest autonomy from their resource dependencies and which are best able to pursue their core mission are those that access a broad but yet specific portfolio of resources.

Our results speak to the ongoing public debate about the optimal sources of support for arts organizations. There are long-standing critiques of arts organizations reliance on 
government funding which, some argue, is a "danger to agency independence, pursuit of agency purposes and internal management style" that compromise the independence of arts organizations (Salamon, 1987: 115). There are counterbalancing concerns about the danger to artistic integrity offered by the increased need of non-profit organizations to pursue commercial activities (Foster \& Bradach, 2007). Our research indicates that, just like the healthy virtues of eating a balanced diet, there is a clear advantage in arts organizations cultivating and maintaining a broad portfolio of revenue streams.

A Hierarchical Model of Resources: Our results suggest that it is not sufficient for arts organization to merely maintain a broad portfolio of resources. To achieve full autonomy to pursue activities that fulfill its social mission, the arts organization may need to access some primary resources in order to gain later access to secondary resources. Resources are not necessarily independent of each other. Unfortuantely our data will not permit us to fully analyze this observation, but rather suggests this as a possible interpretation. However the suggestion has some degree of analogical support from the literature on resources in strategic management where it is clearly understood that basic resources combine into broader competencies or capabilities. Black and Boal (1994: 131) offered an early articulation of this argument, noting that:

...resources are made up of factor networks which have specific interfactor and inter-resource relationships that result in the characteristic traits being evidenced. These strategic resource factor relationships include network type, available substitutes and cogency relationships (compensatory, enhancing and suppressing.)

Their argument, while focused on contributing to the resource-based view, also has implications for RDT. Black and Boal identify a configurational network of twenty-two different resources that appear, in the literature to exist in interdependent relations or configurations. Our model is much simpler, but underscores the need for further and more 
detailed exploration of how organizations can understand the strategic interrelationship, not just of providers of resources and focal organizations, which is the premise of RDT, but also the strategic interrelationship between resources.

Our research also holds practical implications for performing arts organizations. One clear implication is the need for professional management in arts organizations. For profit organizations have long understood the need to carefully manage the relationship between their various products. The top management teams of these organizations devote considerable time and professional expertise to match synergies between resources to their product portfolio. Not for profit firms typically lack the resources and expertise to engage in these strategies. Our research, however, suggests that, not only is there considerable advantage in doing so, but that arts organizations are sufficiently different to require specialized managerial expertise.

Similarly, most research on managing resources in arts organizations has been built on assumptions of how resources are fungible. That is, the assumption is that growth in one source of revenue, say earned revenue, can be substituted with other sources of revenue (Schatteman \& Bingle, 2017). Our emerging configurational model of RDT, however, suggests exactly the opposite. Our study suggests that a configurational approach allows us to more fully see the complexity in resource diversification and its effects on behavioural outcomes. Our work contributes to thinking in resource dependence theory about how organizations generate business models that allow for the appropriate mix of resources, and which allows them and their leaders to gain autonomy, power and the opportunity to thrive.

Most critically, this study offers RDT as an important theoretical lens through which we can achieve a better understanding of how the structure, function and survival of 
arts organizations is determined by the ability of arts organizations to maintain internal autonomy and aesthetic freedom while managing their dependence on external providers of key resources. Our study demonstrates that one way of reducing external dependence is to reconfigure the structure of different sources of resources.

No study, however, can address all of the factors that might contribute to external dependencies. Some research has argued that arts organizations may concentrate their sources of funding when those sources are reliable - and it is the stability, not the diversity, of resources that matters most (Pratt, 2004). In support of this, research shows high variability in the stability of funding offered by different levels of government for arts organizations in Korea, with local government being the least stable and national government being providing the most stable funding (Seo, 2016). Similarly, our data does not offer the granularity to fully distinguish between elite-private and other donors, a distinction that some case study research has shown to be significant (Balfe, 1993). Finally, we note that our sample is distinctly North American where the history of funding arts organizations is notably different from observed institutional practices in Europe (Zimmer \& Toepler, 1999) and Asia (Jung \& Moon, 2007). This study is but a small step toward understanding how arts organizations can creatively manage their external dependencies. 


\section{References}

Adkins, S. 2007. “Cause related marketing: Who cares, who wins?” Pp, 669-693 in Baker, M.J. (Ed.), The Marketing Book, $5^{\text {th }}$ Edititon, New York: Butterworth-Heinmann.

Alexander, V. D. 1996b. "Monet for money? Museum exhibitions and the role of corporate sponsorship". In Arts and Business: An International Perspective on Sponsorship, Edited by: Martorella, Rosanne. 215-223. Westport, CT: Praeger.

Amabile, T. M. 1985. "Motivation and creativity: Effects of motivational orientation on creative writers.” Journal of Personality and Social Psychology 48 (2): 393.

Balfe, J. H. (ed.). 1993. Paying the Piper, Causes and Consequences of Art Patronage. Chicago: University of Illinois Press.

Baumann, S. 2007. A general theory of artistic legitimation: How art worlds are like social movmements. Poetics, 35: 47-65.

Becker, H.S. 1982. Art Worlds. Berkeley, CA: U Cal Berkeley Press.

Black, J.A. \& Boal, K.B. 1994. "Strategic resources: Traits, configurations and paths to sustainable competitive advantage.” Strategic Management Journal, 15(S2): 131-148.

Casciaro, T. \& Piskorski, M.J. 2005. "Power imbalance, mutual dependence and constraint absorption: A closer look at resource dependence theory." Administrative Science Quarterly, 50: 167-199.

Castenar, X. \& L. Campos. 2002. "The determinants of artistic innovation: Bringing in the role of organization." Journal of Cultural Economics. 26: 29-52.

Chambers D.S. 1970. “The Medici of Florence.” Pp 91-111 in: Patrons and Artists in the Italian Renaissance. History in Depth. London: Palgrave Macmillan.

Colbert, F. 2012. "Financing the Arts: Some Issues for a Mature Market." Megatrend Review, 9(1): 83-96.

Dewey, P. 2004. "From arts management to cultural administration". International Journal of Arts Management, 6(3): 13-22.

DiMaggio, P.J. 1986a. “Introduction”, Pp. 3-13 in P.J. DiMaggio (Ed.) Nonprofit Enterprise and the Arts. New York: Oxford University Press.

DiMaggio, P.J. 1986b. "Support from the arts from independent foundations", Pp. 113-139 in P.J. DiMaggio (Ed.) Nonprofit Enterprise and the Arts. New York: Oxford University Press. 
DiMaggio, P.J. 1991. "Constructing an organizational field as a professional project: U.S. art museums, 1920-1940”, Pp. 267-292 in DiMaggio, P.J. \& Powell, W.W. (Eds.), The New Institutionalism in Organizational Analysis, Chicago: Chicago University Press.

Drees, J.M. \& Heugens, P.P. 2013. "Synthesizing and extending resource dependence theory: A meta-analysis". Journal of Management, 39(6): 1666-1698.

File, K.M. \& Prince, R.A. "Cause related marketing and corporate philanthropy in the privately held enterprise”. 1988. Journal of Business Ethics, 17(14): 1529-1539.

Foster, W. \& Bradach, J. L. 2005. "Should nonprofits seek profits?" Harvard Business Review, 83(2): 92-100.

Froelich, K. A. 1999. "Diversification of revenue strategies: Evolving resource dependence in non-profit organizations.” Nonprofit and Voluntary Sector Quarterly. 28: 246-268.

Glynn, M.A. 2000. "When cymbals become symbols: Conflict over organizational identity within a symphony orchestra." Organization Science 11 (3): 285-298.

Hager, M. A. 2001. "Financial vulnerability among arts organizations: A test of the TuckmanChang measures." Nonprofit and Voluntary Sector Quarterly. 30: 376-392.

Hillman, A.J., Withers, M.C. \& Collins, B.J. 2009. "Resource dependence theory: A review." Journal of Management 35(6): 1404-1427.

IEG. 2001. Sponsorship Report, 20(24), 24 December.

Jung, K. \& Moon, M.J. 2007. "The Double-edged sword of Public Resource Dependence: The impact of public resources on autonomy and legitimacy in Korean cultural non-profit organizations. The Policy Studies Journal, 35(2): 205-226.

Katz, D. \& Kahn, R.L. 1978. The Social Psychology of Organizations. New York: Wiley.

Kelley, K.S. 1991. Fund Raising and Public Relations. Mahwah, NJ: Lawrence Erlbaum.

Kirchberg, V. 2003. “Corporate arts sponsorship,” Pp. 143-151 in Ruth Towse (Ed.), A Handbook of Cultural Economics, London: Edward Elgar.

Kramer, M.R. 2009. “Catalytic philanthropy.” Stanford Social Innovation Review, Fall: 30-35.

Lampel, J., Lant, T. \& Shamsie, J. 2000. "Balancing act: Learning from organizing practices in cultural industries." Organization Science, 11(3): 263-269.

McGrath, T., R. Legoux \& S. Senecal 2016. "Balancing the score: The financial impact of resource dependence on symphony orchestras." Journal of Cultural Economics. Published Online 
Meyer, A. D., Tsui, A. S., \& Hinings, C. R. 1993. "Configurational approaches to organizational analysis." Academy of Management Journal, 36: 1175-1195.

Mulcahey, KV. 2000. "The government and cultural patronage.” Pp. 138-168 in Cherbo, J.M. and Wyszomirski, M.J. (Eds.), The Public Life of the Arts in America, Newark, NJ: Rutgers University Press.

Oliver, C. 1991. Network relations and loss of organizational autonomy. Human Relations, 44: 943-961.

Porter, M.E. \& Kramer, R. 2002. "The competitive advantage of corporate philanthropy.” Harvard Business Review, 80(12): 56-88.

Pfeffer, J. \& Salancik, G.R. 1978. The External Control of Organizations: A Resource Dependence Approach. Palo Alto, CA: Stanford University Press.

Pratt, J. 2004. "The Dynamics of Funding: Considering reliability and autonomy. Non-profit Quarterly, Summer: 8-13.

Saidel, J.R. 1991. "Resource interdependence: The relationship between state agencies and nonprofit organizations." Public Administration Review, 51(6): 543-553.

Salaman, L.M. 1987. "Partners in public service." Pp. 99-117 in Powell, W. W. (Ed.), The Nonprofit Sector: A Research Handbook. New Haven, CT: Yale University Press.

Schatteman, A.M. \& Bingle, B. 2017. "Government funding of arts organizations: Impact and implications." The Journal of Arts Management, Law and Society, 47(1): 34-46.

Seo, J.W. 2016. "Resource dependence patterns and organizational behavior/structure in nonprofit organizations". Non-profit Management \& Leadership, 27(2): 219-236.

Thornton, S. 2008. Seven Days in the Art World. New York: WW Norton.

Ulrich, D. \& Barney, J.B. 1984. "Perspectives in organizations: Resource dependence, efficiency and population." Academy of Management Review, 9: 471-481.

Useem, M. 1987. "Corporate philanthropy”, Pp. 34-359 in W. Powell (Ed.) The Non-Profit Sector: A Research Handbook. New Haven, CT: Yale University Press.

Varadarajan, P.R. \& Menon, A. 1988. "Cause-related marketing: A coalignment of marketing strategy and corporate philanthropy”. The Journal of Marketing, 52(3): 58-74.

Wyszomirski, M.J. 2002. "Arts and culture". In Salamon, L.B. (Ed.), The State of Nonprofit America, Washington, DC: Brookings University Press. 